\title{
A Decade of Octreotide
}

Somatostatin, a peptide hormone initially isolated from ovine hypothalami, has been documented to inhibit the release of growth hormone. It soon became evident that this peptide was not only present in the brain but was widely distributed in the stomach, the gastrointestinal tract and the pancreas. By 1980, the gene encoding for prosomatostatin had been identified and it became evident that different molecular forms are present in the body. Later on, different receptors for somatostatin were identified and it became clear that the different molecular forms and the different receptors are part of a complicated control system which regulate a variety of body functions. Somatostatin molecules exert profound inhibitory functions, not only on growth hormone secretion but also on many gastrointestinal functions. These different effects form the basis for an enormous therapeutic potential of somatostatin in different diseases. The short half-life of natural somatostatin which necessitates a continuous intravenous infusion has made it difficult to transform the natural peptide into a successful drug. It was therefore a major step forward when a synthetic analogue of somatostatin, octreotide, was synthesized and became available for clinical use in the mid-eighties. For over a decade, subcutaneous octreotide has proven effective in the treatment of acromegaly and in several clinical areas relating to gastroenterology and digestive surgery. The ability of octreotide to control symptoms such as diarrhea or flush caused by gut-neuroendocrine tumors soon became evident. Subsequently, octreotide was used in other forms of secretory diarrhea (AIDS-related diarrhea, idiopathic diarrhea, diabetic diarrhea) but also in the management of pancreatic disorders (pancreatic fistulae, prevention of complications following pancreatic surgery). Somatostatin analogues including octreotide have been shown to reduce pressure in the splanchnic circulation, an effect that was exploited in the management of variceal and nonvariceal hemorrhages.

Despite a widespread therapeutic application, octreotide seems to be a safe drug free of major side effects. Most of the reported side effects are gastrointestinal in nature and include steatorrhea, bloating, minor nausea, gallstones and mild forms of glucose intolerance. Recently a new formulation of octreotide, octreotide LAR ${ }^{\circledR}$ (longacting repeatable), was developed which enables once-amonth administration. Octreotide $\mathrm{LAR}^{\circledR}$ combines over a decade of proven benefits of the subcutaneous octreotide administration with a more convenient formulation for long-term treatment of a variety of diseases. Oncemonthly administration should improve patient acceptability and compliance; it represents a significant advance in the management of a number of conditions associated with excessive peptide secretion (acromegaly, neuroendocrine tumors). There is no doubt that additional indications will emerge as investigations continue. Treatment of certain gastrointestinal cancers and prevention of variceal bleeding are two clinical areas which are currently under investigation. A decade of octreotide has been beneficial for many patients; hopefully many more will be able to take advantage of this fascinating peptide.
Bern and Basel

January 1999
Markus W. Büchler Christoph Beglinger

\begin{tabular}{ll}
\hline KARGER & (1999 S. Karger AG, Basel \\
Fax +41 61 306 12 34 & Accessible online at: \\
$\begin{array}{l}\text { E-Mail karger@karger.ch } \\
\text { www.karger.ch }\end{array}$ & $\begin{array}{l}\text { Acces-0001\$17.50/0 } \\
\text { http//BioMedNet.com/karger }\end{array}$
\end{tabular}

